\title{
Instrumental characterization of clay by XRF, XRD and FTIR
}

\author{
PREETI SAGAR NAYAK* and B K SINGH \\ Department of Chemistry, Govt. M.H. College of Home Science and Science for Women, Jabalpur 482 002, India
}

MS received 18 September 2006; revised 11 April 2007

\begin{abstract}
Instrumental characterizations of the clay were performed by different techniques such as XRF, XRD and FTIR. XRF shows the chemical compositions of the clay where Al-oxide and silica oxide are present in major quantity whereas XRD confirms the presence of these minerals in clay. FTIR studies show the presence of quartz, alumina, haematite and different mineral matters.
\end{abstract}

Keywords. Instrumental characterization; XRF; XRD; FTIR.

\section{Introduction}

Natural clay minerals are well known and familiar to mankind from the earliest days of civilization. Because of their low cost, abundance in most continents of the world, high sorption properties and potential for ion exchange, clay materials are strong candidates as adsorbents. Clay materials possess a layered structure and are considered as host materials. They are classified by the differences in their layered structures. There are several classes of clays such as smectites (montmorillonite, saponite), mica (illite), kaolinite, serpentine, pylophyllite (talc), vermiculite and sepiolite (Shichi and Takagi 2000). The adsorption capabilities result from a net negative charge on the structure of minerals. This negative charge gives clay the capability to adsorb positively charged species. Their sorption properties also come from their high surface area and high porosity (Alkan et al 2004). Montmorillonite clay has the largest surface area and highest cation exchange capacity. Its current market price (about US\$ $0 \cdot 04-0 \cdot 12 / \mathrm{kg}$ ) is considered to be 20 times cheaper than that of activated carbon (Babel and Kurniawan 2003). In recent years, there has been an increasing interest in utilizing clay minerals such as bentonite, kaolinite, diatomite and fullers earth for their capacity to adsorb not only inorganic but also organic molecules. They showed that this naturally occurring material could act as a substitute for activated carbon as an adsorbent due to its availability and low cost, and its good sorption properties.

Clay is composed mainly of silica, alumina and water, frequently with appreciable quantities of iron, alkalies and alkali earths (Ralph 1968). Two structural units are involved in the atomic lattices of most clay minerals. One unit

*Author for correspondence (preetisagarnayak@rediffmail.com) consists of closely packed oxygens and hydroxyls in which aluminium, iron and magnesium atoms are embedded in an octahedral combination so that they are equidistant from six oxygens or hydroxyls. The second unit is built of silica tetrahedrons. The silica tetrahedrons are arranged to form a hexagonal network that is repeated indefinitely to form a sheet of composition, $\mathrm{Si}_{4} \mathrm{O}_{6}(\mathrm{OH})_{4}$ (Ralph 1968). A large number of researchers determined semi-quantitative clay mineral composition on the basis of area under X-ray diffraction peak duly corrected by appropriate factors accounting for variation of scattering due to variation of angle. The literature on quantitative clay mineral analysis has been reviewed from time to time (Mukherjee et al 1971; Ghosh and Raychaudhuri 1974; Ghosh and Kapoor 1982; Ghosh and Datta 1996). Later on, many others (Bhattacharyya and Sidhu 1987; Ravikumar et al 1991; Agrawal and Singh 1995; Sidhu and Ghosh 1996) revealed the occurrence of a wide spectrum of minerals.

Numerous studies have been carried out on the behaviour of the exchanged, now organophilic clay (Gibbons and Soundararajan 1988; Conner 1990; Montgomery et al 1991; Faschan et al 1993). Dentel et al (1995) used trimethylammonium for the removal of 1,2,4-trichlorobenzene in the presence of tannic acid. The FTIR study of water adsorption was carried out by Stevens and Anderson (1996a). Similarly, the orientations of trimethyl phenylammonium (TMPA) in montmorillonite, as well as its implications in the adsorption of aromatic compounds, have been studied by Stevens and Anderson (1996b). Kramer (2000) and Uribe (2000) studied the adsorption behaviour of this type of organoclays. This will pave the way for using the results of clay research in a mutually beneficial way for increasing soil productivity. The knowledge developed in the field of clay mineralogy have been of some use in genetic and taxonomic studies of soil as well. Hence, this paper deals with the characterization of clay with the help of this technique. 


\section{Experimental}

The characterization of clay is carried out with a number of experimental approaches in order to investigate all the relevant features. Clay was obtained from the mines of Katni district of Madhya Pradesh. This sample was fractionated into different fractions of varying particle sizes using standard sieves of mesh sizes having geometrical mean particle diameters 140,100 and $50 \mu \mathrm{m}$. The chemical constituents and $\mathrm{LOI}$ at $800^{\circ} \mathrm{C}$ were determined by the Indian standard method (Indian Standard Methods of Chemical Analysis of Fireclay and Refractory Materials 1960).

The clay was analysed for its vibrational spectra with the aid of Fourier transform infrared spectroscopy using Perkin Elmer 1800 model instrument in the range 450$4000 \mathrm{~cm}^{-1}$ as potassium bromide pellet.

XRD patterns of clay were obtained on a powder X-ray diffractometer Model Philips with $\mathrm{CuK}_{\alpha}$ radiation having a scanning speed of $0.04 \%$. The clay was subjected to $\mathrm{XRF}$ to analyse the chemical composition or elements present in the sample.

\section{Results and discussion}

\subsection{Characterization of clay particle}

It is clear from table 1 that the chemical analysis of the clay contains alumina, silica and calcium in major quantities and other elements in minor quantities. The loss on ignition value indicates that clay has lower carbonaceous matter and higher mineral matter contents. For understanding the nature of phenol sorption on clay, XRF, XRD and FTIR studies were performed using raw sorbents, which are described in the following sections.

\subsection{XRF characterization}

It was performed to know the chemical compositions of the minerals that are present in the clay. The data given in table 2 shows that the alumina and silica oxide are present in major quantities while other minerals are present in trace amounts. This confirms the chemical analysis of clay.

\subsection{XRD characterization}

The presence of above minerals were further tested by XRD studies. XRD is used to determine the mineralogical composition of the raw material components as well as qualitative and quantitative phase analysis of multiphase mixtures. The occurrences of minerals in clay were identified by comparing ' $d$ ' values (Selected Powder Diffraction Data for Minerals 1974; Powder Diffraction File Search Manual Minerals 1974). The possible minerals with their ' $d$ ' values present in the adsorbents are given in table 3. No quantitative estimation phases in these adsorbents have been made but their characterization of XRD patterns indicates the presence of quartz, kaolinite, hematite, illite, and tridymite as the major phases. Further the occurrence of the above minerals in the aforesaid adsorbents was confirmed by FTIR study.

\subsection{FTIR characterization}

FTIR studies of these adsorbents help in the identification of various forms of the minerals present in the clay. The coupled vibrations are appreciable due to the availability of various constituents. Nevertheless, observed bands (in the range, 4000-500 $\mathrm{cm}^{-1}$ ) have been tentatively assigned. In the IR studies of clay, the $\mathrm{Si}-\mathrm{O}$ stretching vibrations

Table 2. Chemical analysis of fractions of clay.

\begin{tabular}{|c|c|}
\hline Chemical composition & Weight (\%) \\
\hline $\mathrm{SiO}_{2}$ & 28.977 \\
\hline $\mathrm{Al}_{2} \mathrm{O}_{3}$ & $14 \cdot 081$ \\
\hline $\mathrm{Fe}_{2} \mathrm{O}_{3}$ & $1 \cdot 201$ \\
\hline $\mathrm{CaO}$ & $0 \cdot 183$ \\
\hline $\mathrm{MgO}$ & 0.638 \\
\hline $\mathrm{TiO}_{2}$ & $0 \cdot 875$ \\
\hline $\mathrm{K}_{2} \mathrm{O}$ & $0 \cdot 382$ \\
\hline $\mathrm{MnO}$ & $0 \cdot 036$ \\
\hline $\mathrm{SrO}$ & $0 \cdot 001$ \\
\hline $\mathrm{Na}_{2} \mathrm{O}$ & $2 \cdot 547$ \\
\hline $\mathrm{Ni}$ & $0 \cdot 003$ \\
\hline $\mathrm{Zn}$ & $0 \cdot 005$ \\
\hline $\mathrm{V}$ & $0 \cdot 011$ \\
\hline $\mathrm{P}$ & $0 \cdot 018$ \\
\hline $\mathrm{Cr}$ & 0.009 \\
\hline $\mathrm{Cu}$ & 0.003 \\
\hline
\end{tabular}

Table 1. Chemical analysis of clay.

\begin{tabular}{lc}
\hline Chemical composition & Weight (\%) \\
\hline $\mathrm{SiO}_{2}$ & $48 \cdot 12$ \\
$\mathrm{Al}_{2} \mathrm{O}_{3}$ & 34.54 \\
$\mathrm{Fe}_{2} \mathrm{O}_{3}$ & $2 \cdot 48$ \\
$\mathrm{CaO}$ & $0 \cdot 83$ \\
$\mathrm{MgO}$ & $0 \cdot 50$ \\
$\mathrm{TiO}_{2}$ & $0 \cdot 40$ \\
$\mathrm{LOI}\left(800^{\circ} \mathrm{C}\right)$ & $12 \cdot 44$ \\
\hline
\end{tabular}

Table 3. X-ray diffraction ' $d$ ' values of clay fraction.

\begin{tabular}{lc}
\hline$d(\AA)$ & Possible mineral \\
\hline $4 \cdot 2754,1 \cdot 5441,1 \cdot 3864$ & Quartz \\
$3 \cdot 4354,2 \cdot 5505,1 \cdot 3781$ & Alumina \\
$2 \cdot 6990,1 \cdot 6957,2 \cdot 2001$ & Hematite \\
$3 \cdot 8057,3 \cdot 4354,2 \cdot 2903$ & Tridymite \\
$3 \cdot 3462,3 \cdot 0965,2 \cdot 2844$ & Illite \\
$4 \cdot 1876,2 \cdot 5509,3 \cdot 4023$ & Kaolinite \\
\hline
\end{tabular}


Table 4. Important IR bands of clay along with their possible assignments.

\begin{tabular}{lcl}
\hline Band $\left(\mathrm{cm}^{-1}\right)$ & Transmittance (\%) & \multicolumn{1}{c}{ Assignments } \\
\hline $3696 \cdot 7$ & $27 \cdot 3$ & Al---O-H str. \\
$3622 \cdot 5$ & $13 \cdot 5$ & Al---O-H (inter-octahedral) \\
$3450 \cdot 4$ & $50 \cdot 2$ & H-O-H str. \\
$1633 \cdot 4$ & $91 \cdot 4$ & H-O-H str. \\
$1033 \cdot 3$ & $7 \cdot 2$ & Si-O-Si, Si-O str. \\
$914 \cdot 5$ & $32 \cdot 6$ & Al---O-H Str. \\
$790 \cdot 9$ & 27.5 & Si-O str., Si-O-Al str. \\
& & (Al, Mg)---O-H. \\
$693 \cdot 4$ & 66.8 & Si-O- (Mg, Al) str. \\
538.8 & 29.9 & Si-O str., Si-O-Al str. \\
468.9 & $12 \cdot 3$ & Si-O str., Si-O-Al str. \\
\hline
\end{tabular}

were observed at $790.9 \mathrm{~cm}^{-1}, 693.4 \mathrm{~cm}^{-1}, 538.8 \mathrm{~cm}^{-1}$ and $468.9 \mathrm{~cm}^{-1}$ showing the presence of quartz (Marel and Bentelspacher 1976). The appearance of $v(\mathrm{Si}-\mathrm{O}-\mathrm{Si})$ and $\delta(\mathrm{Si}-\mathrm{O})$ bands also support the presence of quartz (Marel and Bentelspacher 1976), a strong band at $3696.7 \mathrm{~cm}^{-1}$, $3622.5 \mathrm{~cm}^{-1}$ and $3450.4 \mathrm{~cm}^{-1}$ indicate the possibility of the hydroxyl linkage. However, a broad band at $3450.4 \mathrm{~cm}^{-1}$ and a band at $1633.4 \mathrm{~cm}^{-1}$ in the spectrum of clay suggests the possibility of water of hydration in the adsorbent. The inter layer hydrogen bonding in clay is assigned by a characteristics band at $3622 \cdot 5 \mathrm{~cm}^{-1}$. Most of the bands such as $3696.7 \mathrm{~cm}^{-1}, 3622.5 \mathrm{~cm}^{-1}, 3450.4 \mathrm{~cm}^{-1}, 1033.3 \mathrm{~cm}^{-1}$, $914.5 \mathrm{~cm}^{-1}, 790.9 \mathrm{~cm}^{-1}, 693.4 \mathrm{~cm}^{-1}, 538.8 \mathrm{~cm}^{-1}, 468.9 \mathrm{~cm}^{-1}$ show the presence of kaolinite (Tuddenham and Lyon 1960). The vibrations observed at $914.5 \mathrm{~cm}^{-1}$ indicate the possibility of the presence of hematite (Gadsen 1975). The presence of bands at $3696.7 \mathrm{~cm}^{-1}, 3622.5 \mathrm{~cm}^{-1}$, $3450.4 \mathrm{~cm}^{-1}, \quad 2369.8 \mathrm{~cm}^{-1}, \quad 1633.4 \mathrm{~cm}^{-1}, \quad 1033.3 \mathrm{~cm}^{-1}$, $914.5 \mathrm{~cm}^{-1}$ and $790.9 \mathrm{~cm}^{-1}$ indicate the possibility of the presence of illite (Wolf 1963), whereas $3622.5 \mathrm{~cm}^{-1}$, $1633.4 \mathrm{~cm}^{-1}, 1033.3 \mathrm{~cm}^{-1}$ are indicative of gypsum and $693.4 \mathrm{~cm}^{-1}$ shows the possibility of the presence of calcite (Gadsen 1975). The corresponding values are given in table 4.

Thus the results of IR are quite helpful in the identification of various forms of minerals present in the used sorbents. IR spectra of these sorbents show adsorption band at $3622.5 \mathrm{~cm}^{-1}$ of clay corresponding to $\mathrm{H}_{2} \mathrm{O}$ vibrations, indicating the hydrous nature of these materials and the presence of hydroxyl linkage. However, owing to the mixing of various overtones and complexity of the spectrum of clay, distinct assignments of various other vibrations have not been made.

\section{Conclusions}

The chemical analysis, XRF, XRD and FTIR show that clay is mainly constituted of alumina and silica in major quantities and iron, calcium, magnesium oxide and other ele- ments in minor quantities. The loss on ignition value indicates that clay has lower carbonaceous matter and higher mineral matter contents. X-ray diffraction study shows the presence of quartz, kaolinite, hematite, illite and tridymite as major phases. The presence of above minerals were further confirmed by FTIR analysis.

\section{Acknowledgements}

The authors thank the authorities of the Central Drug Research Institute, Lucknow, the Central Electrochemical Research Institute, Karaikudi and the Indian Institute of Technology, Mumbai, for providing FTIR, XRD and $\mathrm{XRF}$ results, respectively.

\section{References}

Agrawal H P and Singh G N 1995 Clay Res. 141

Alkan M, Demirbas Ö, Celikc apa S and Dogan M 2004 J. Hazardous Mater. 116135

Babel S and Kurniawan T A 2003 J. Hazardous Mater. B97 219 Bhattacharyya D and Sidhu P S 1987 Clay Res. 623

Conner J 1990 Chemical fixation and solidification of hazardous wastes (New York: Van Nostrand Reinhold)

Dentel S K, Bottero J Y, Khatib K, Demougeot H, Duguet J and Anselm C 1995 Water Res. 291273

Faschan A, Cartledge F and Tittlebaum M 1993 J. Environ. Sci. Health A28 585

Gadsen J A 1975 Infrared spectra of minerals and related inorganic compounds (London: Butterworths)

Ghosh S K and Raychaudhuri S P 1974 Bull. Indian Nat. Sci. 9 143

Ghosh S K and Kapoor B S 1982 in Review of soil research in India Part 2 (New Delhi: Indian Society of Soil Science)

Ghosh S K and Datta S C 1996 Indian Soc. Nuclear Tech. Agric. Biol. 98

Gibbons J and Soundararajan R 1988 The nature of chemical bonding between modified clay minerals and organic waste materials (Am Lab) pp. 38-46

Indian Standard Methods of Chemical Analysis of Fireclay and Refractory Materials 1960 IS: 1527

Kramer M J 2000 Azo dye sorption from wastewater streams via organophilic clay sorption, M.S. Thesis, University of Cincinnati, Cincinnati, Ohio

Marel H M V and Bentelspacher H 1976 Atlas of infrared spectroscopy of clay minerals and their admixtures (NY: Elsevier Science Publishers)

Montgomery D, Sollars C, Perry R, Tarling S, Barnes P and Henderson E 1991 Waste Manag. Res. 9113

Mukherjee S K, Das S C and Raman K V 1971 in Review of soil research in India (New Delhi: Indian Society of Soil Science)

Powder Diffraction File Search Manual Minerals 1974 Joint Committee on powder diffraction standards, USA

Ralph E Grim 1968 Clay mineralogy (New York: McGraw Hill Book Co.)

Ravikumar D S R, Mahendra Singh and Ghabru S K 1991 Clay Res. 1064 
Selected Powder Diffraction Data for Minerals 1974 Data book, Joint Committee on powder diffraction standards, USA, 1st ed. Shichi T and Takagi K $2000 \mathrm{~J}$. Photochem. Photobiol. C: Photochem. Rev. 1113

Sidhu G S and Ghosh S K 1996 Clay Res. 15

Stevens J and Anderson S 1996a Clays Clay Miner. 44132
Stevens J and Anderson S 1996b Clays Clay Miner. 44142 Tuddenham W M and Lyon R J P 1960 Anal. Chem. 321630 Uribe A 2000 Solidification/stabilization of hazardous wastes using organophilic clays, M.S. thesis, University of Cincinnati, Cincinnati, Ohio

Wolf R G 1963 Am. Mineral. 48390 